\title{
Omura's whale (Balaenoptera omurai ) stranding on Qeshm Island, Iran: further evidence for a wide (sub)tropical distribution, including the Persian Gulf
}

Sharif Ranjbar (a), Mohammad Sayed Dakhteh (b), Koen Van Waerebeek (c,d) *,

a Department of Marine Biology, Hormozgan University, Hormozgan, Iran

b Head, Qeshm Environment Administration, Qeshm Free Area, Qeshm City, Qeshm Island, Iran

c Adviser to Marine Mammal Unit, Qeshm Environment Administration, Qeshm Free Area, Qeshm Island, Iran

d Peruvian Centre for Cetacean Research, Centro Peruano de Estudios Cetológicos (CEPEC), Museo de

Delfines, Lima 20, Peru

\begin{abstract}
A small, juvenile rorqual live-stranded on Qeshm Island, Iran, in the northern Strait of Hormuz (Persian Gulf) in September 2007. Cause of stranding remains unknown but the whale (QE22.09.2007) showed no severe traumatic injuries nor was emaciated. Based on at least seven morphological features, considered diagnostic in combination, allowed a positive identification as Omura's whale Balaenoptera omurai. Features included diminutive body size $(397 \mathrm{~cm})$, a large number of ventral grooves $(\mathrm{n}=82)$ extending caudad of the umbilicus, a strongly falcate dorsal fin, asymmetric colouration of the head (especially lower jaws) reminiscent of fin whale, including three unilateral dark stripes, faint/incomplete lateral rostral ridges, record low number of short, broad baleen plates (204 in right jaw). The likelihood for the existence of a local $B$. omurai population in the eastern Persian Gulf or northern Arabian Sea seems higher than the wandering of a very young animal or mother/calf pair from any of the known distant distribution areas in the eastern Indian Ocean or SW Indian Ocean (Madagascar). This is the first record of B. omurai in the NW Indian Ocean.
\end{abstract}

Keywords: Omura's whale; distribution; Balaenopteridae; Persian Gulf; Iran; external morphology.

\footnotetext{
* Corresponding author. Email: corewam@yandex.com
} 


\section{Introduction}

A small rorqual (Balaenoptera sp.) with a body length of $397 \mathrm{~cm}$ stranded at N2656'17.88", E56 ${ }^{\circ} 16^{\prime} 42.09 "$ on Qeshm Island, Iran, in the northern Strait of Hormuz, Persian Gulf, on 22 September 2007. The diminutive rorqual, evidently a calf or juvenile, had stranded alive on 21 September 2007, at an indeterminate time. During the night a team of local volunteers attempted to rescue the animal by keeping it wet with the plan to refloat it with rising tide, actions which were filmed by Mr. Besharati Asghar. Predictably the rescue failed and the whale died in situ.

Based on external morphological characteristics we here identify the Qeshm rorqual as an Omura's whale Balaenoptera omurai Wada, Oishi \& Yamada 2003. This recently described, small rorqual species, with an adult size of barely $11.7 \mathrm{~m}$, was until 2015 thought to be distributed exclusively in tropical and subtropical waters of the southwestern Pacific and the eastern Indian Ocean (Wada et al. 2003; Jefferson et al. 2008; Reilly et al. 2008a). Cerchio et al. (2015) extended known range to the Southwestern Indian Ocean when reporting on a population resident in coastal waters of northern Madagascar. These authors documented external morphology in some detail from underwater photography, which resulted essential in the present analysis. Simultaneously, Jung et al. (2015) demonstrated at least occasional distribution of B. omurai into the Northeast Atlantic Ocean, following the genetic identification of a $398 \mathrm{~cm}$ juvenile stranded on an Mauritanian beach in 2013. Jung et al. (2015) advanced two hypotheses, either an unrecognised Atlantic population or, less likely, an inter-oceanic vagrant.

The main significance of the Qeshm specimen resides in the fact that $B$. omurai has not before been documented from the Persian Gulf, Iran and the Northwestern Indian Ocean. The possible occurrence off Iran was recognized by Braulik et al. (2010).

\section{Material and Methods}

On 22 September, two of us (SR, MSD) examined, measured and photographed the fresh carcass, henceforth referred to as specimen QE22.09.2007. Multiple shallow cuts and abrasion injuries, apparently linked to the stranding event, were present but there was no indication of major trauma or emaciation. As the specimen was not necropsied and no tissue samples were collected, the cause of death will remain unknown. Considering that it was initially thought to be a Bryde's whale, the carcass was buried on the beach for later retrieval but, washed out during a spring tide, it eventually was lost. Numerous photographs $(\mathrm{n}=124)$ and a video of both the live and freshly dead ( $<12$ hours) whale were deposited at the Qeshm Environment Administration at Qeshm City, with back-up copies now archived at the Peruvian Centre for Cetacean Research, Lima.

As to positively identify QE22.09.2007 based on its distinctive morphology and pigmentation pattern, we followed an inferential process in which at least seven morphologic features described for $B$. omurai (Wada et al., 2003; Jefferson et al., 2008; Cerchio et al., 2015) were demonstrated to be present and, combined, deemed diagnostic for B. omurai. QE22.09.2007 was also distinguished from the other seven known rorqual species (genus Balaenoptera Lacépède) in a differential diagnosis, discarding blue whale, $B$. musculus (Linnaeus, 1758); fin whale, B. physalus (Linnaeus, 1758); sei whale, B. borealis Lesson, 1828; Bryde's whale, B. brydei Olsen, 1913; Eden's whale, B. edeni Anderson, 1879; Antarctic minke whale, B. bonaerensis Burmeister, 1867; and common minke whale, B. acutorostrata Lacépède, 1804.

Although increasing evidence (e.g. Wada et al., 2003; Sasaki et al., 2006) suggests that large-sized Bryde's whales (B. brydei Olsen, 1913) form a clade distinct at specific level from the smaller-sized Eden's whale ( $B$. edeni Anderson, 1879), several authors continue to defend a conservative view of conspecificity where $B$. brydei is considered a junior synonym of B. edeni (e.g. Best, 2003; Reilly et al. 2008b). Although we tend to agree with dual species (Wada et al. 2003), in practical terms it remains difficult to assign individual specimens to brydei or edeni forms since most published variation (ranges) in external measurements, meristics and other phenotypic features span the pooled intraspecific variation of both large and small forms 


\section{Short Title: Omura's whale in the Persian Gulf}

of Bryde's whales sensu lato.

We counted the throat (ventral) grooves from high-resolution photographs at the cross-section of the pectoral fins over an $1 / 2$ exposed throat (i.e. from the ventral midline up to one flipper). Next, we added the count of the few grooves lateral to one pectoral fin, visible from a side view photo. Throat grooves were counted several times independently, then averaged. Finally, we multiplied by 2 to provide the total number of throat grooves.

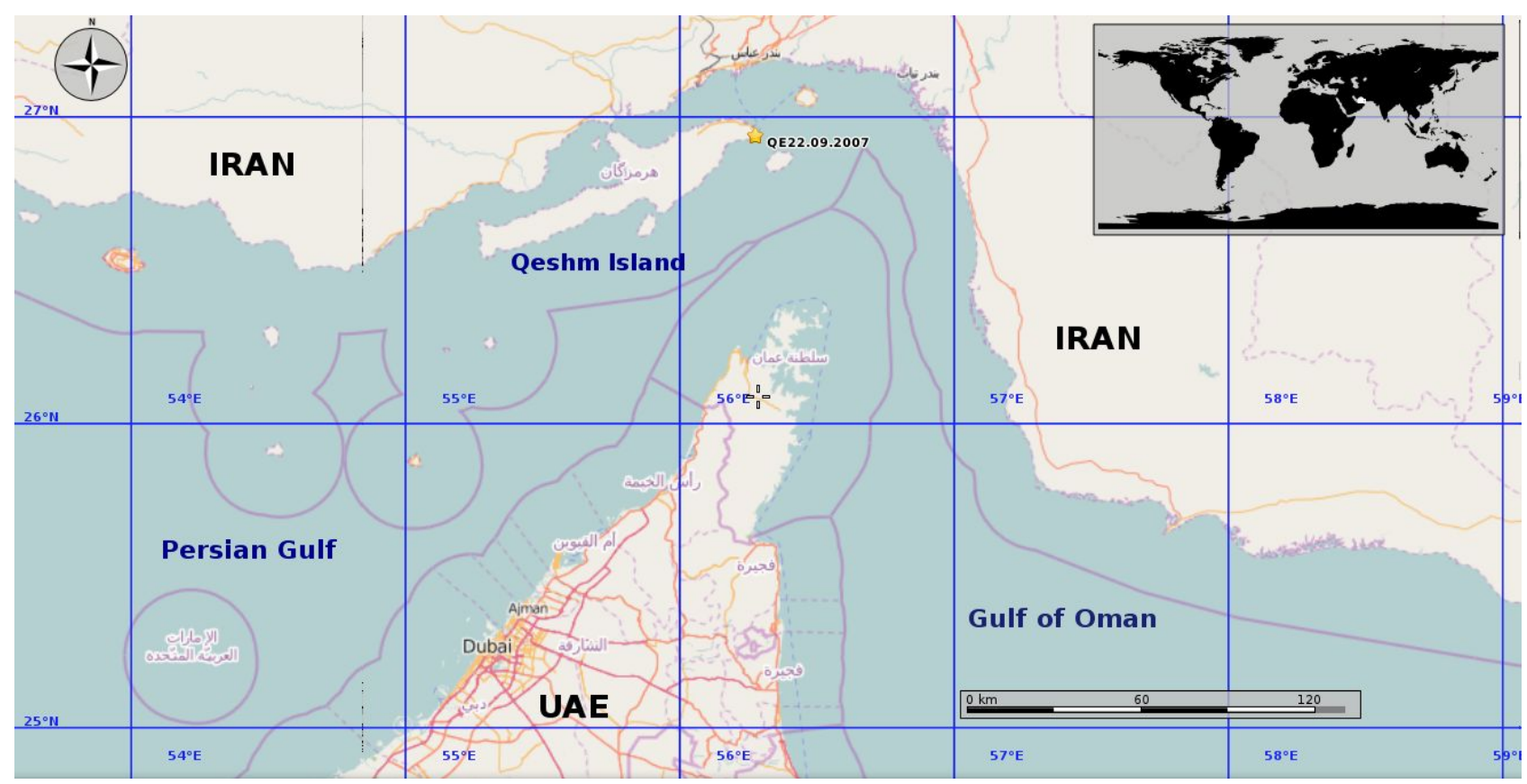

Figure 1. Map showing the stranding location of specimen QE22.09.2007 (yellow star) on the eastern tip of Qeshm Island, Iran, located at the Strait of Hormuz which links the Persian Gulf to the Gulf of Oman in the Northeast Indian Ocean.

\section{Results and Discussion}

Below we discuss the morphologically diagnostic features which, one by one distinguish specimen QE22.09.2007 from some, most or all other balaenopterid species minus B. omurai.

\section{Diminutive body size}

Body length of QE22.09.2007 measured $397 \mathrm{~cm}$. Interestingly, a B. omurai calf, genetically identified as such, that stranded in Mauritania measured a virtually identical $398 \mathrm{~cm}$ (Jung et al., 2015; Mullié et al., 2015). The fully healed umbilicus of QE22.09.2007 (Figure 2) indicated an age class of, as a minimum, a several weeks-old neonate, but probably considerably older. QE22.09.2007 was significantly smaller than neonate length for blue whale (B. musculus), fin whale (B. physalus) and sei whale (B. borealis), which definitively discards the three larger balaenopterids from the differential diagnosis due to their large body size. In comparison, neonate size for Bryde's whales ranges 3.81-3.96 cm (Best, 2007). Antarctic minke (B. bonaerensis) and common minke whales (B. acutorostrata), smaller still, range respectively 2.7-2.9 m (Best, 2007) and 2.0-2.8 m (Jefferson et al., 2008), species that cannot be excluded based on body size.

\section{Large number of ventral grooves that extend caudad of umbilicus}

From photographs it was determined that specimen QE22.09.2007 had about 82 narrow throat grooves which extended caudad of the umbilicus (Figure 2). This exceptionally large number is consistent with the 80-90 throat grooves reported for B. omurai (Wada et al., 2003) and the 'minimum of 70' in a juvenile specimen from Mauritania (Jung et al., 2015) that was similar to QE22.09.2007. Moreover, the lengthy throat grooves 
bioRxiv preprint doi: https://doi.org/10.1101/042614; this version posted March 7, 2016. The copyright holder for this preprint (which was not certified by peer review) is the author/funder. All rights reserved. No reuse allowed without permission.

\section{Short Title: Omura's whale in the Persian Gulf}

extended markedly caudad to the pectoral fin tips, as is evident also in the Mauritania individual (Jung et al., 2015).

Such a high number, and far caudad extension, of throat grooves distinguish QE22.09.2007 from $B$. bonaerensis which, on average, has merely some 65 grooves (range $=44-76$ ) that extend in the midline from the tip of the lower jaw to just anteriad of the umbilicus (Best, 2007). These features distinguish QE22.09.2007 also from dwarf minke whale (B. acutorostrata subsp.) which has even less throat grooves, namely 44-66 at the cross-section of the flippers (Kato and Fujise, 2000) and grooves that extend only to anteriad of the umbilicus (Best, 2007). Ventral groove characteristics by itself exclude both minke whale species.

In Bryde's whales the major ventral grooves number 42-54 and extend from the chin as far back as the umbilicus (Olsen, 1913; Best, 2007). Jefferson et al. (2008) indicated a higher upper range (40-70) for $B$. brydei but even that maximum does not compare positively with the 82 grooves observed in QE22.09.2007.

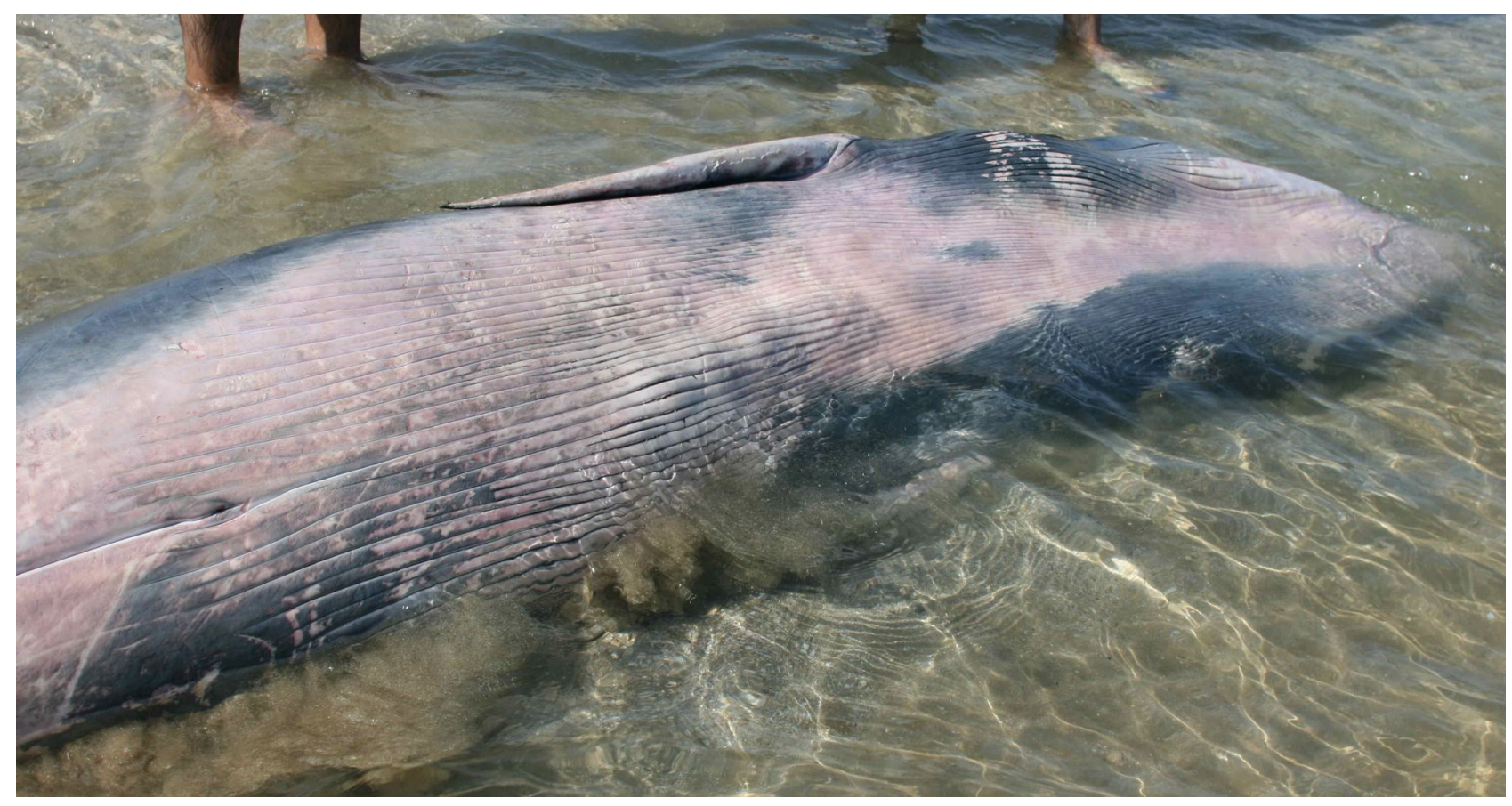

Figure 2. Ventral view of specimen QE22.09.2007, showing diagnostically large number of throat grooves $(n=82)$, which extended caudad of the fully healed umbilicus. Note also the asymmetric ventral colouration pattern (see text).

Strongly falcate dorsal fin.

Omura's whales have a strongly falcate and pointed dorsal fin (Wada et al., 2003; Jefferson et al., 2008; Cerchio et al., 2015), probably more consistently backswept than in any other rorqual species (Figure 3), especially in adults. Some growth variation may exist. Indeed, in several Omura's whales, the often elongated tip points backwards at a $90^{\circ}$ angle from vertical (e.g., photo on p.58, by T. Yamada in Jefferson et al., 2008; and supplementary material of Cerchio et al., 2015). This results in a very low dorsal fin height/length-at-base (H/L) ratio, 0.41 in the Yamada specimen. In QE22.09.2007, the dorsal fin was also strongly falcate and formed a $90^{\circ}$ angle (Figure 3). Height and length at base measured, respectively, $7.5 \mathrm{~cm}$ and $18.0 \mathrm{~cm}$, also resulting in a low $\mathrm{H} / \mathrm{L}$ ratio of 0.42 . 


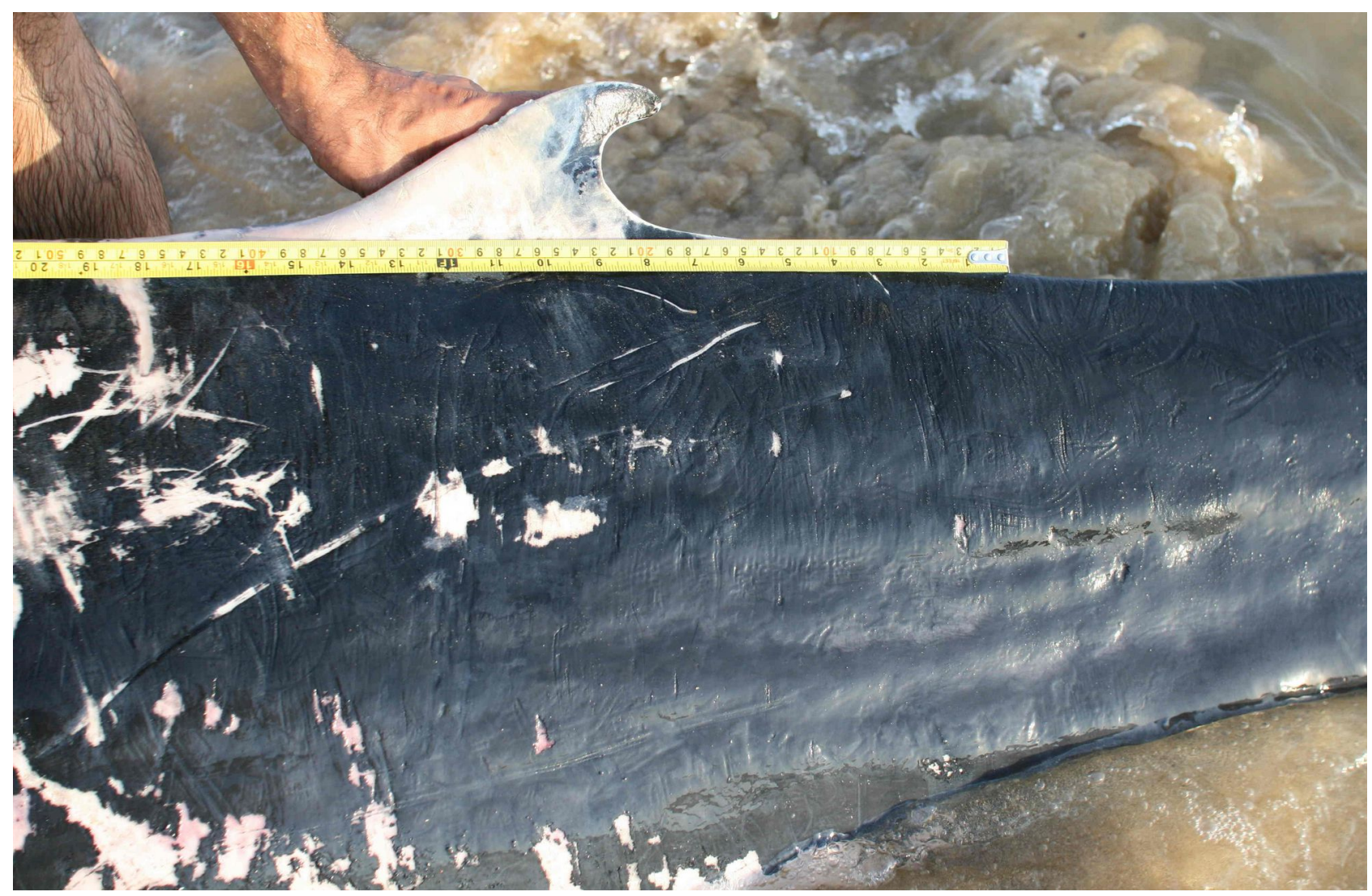

Figure 3. The strongly falcate, but relatively low, dorsal fin of QE22.09.2007, with tip pointing backwards seems a consistent characteristic for $B$. omurai. Indications are that the recurvedness accentuates with growth.

\section{Asymmetric colouration pattern}

Overall the colouration pattern of $B$. omurai resembles that of the fin whale Balaenoptera physalus (Wada et al. 2003; Jefferson et al., 2008). In QE22.09.2007 (Figure 2), as in B. omurai, the left side of the throat is darkly pigmented while much of the remaining ventral surface is mostly lightly coloured (Wada et al., 2003). However the lower lips, i.e. the skin covering the mandibula were a slightly darker grey (Figure 4), also clearly visible, albeit not discussed, in an adult female B. omurai from Madagascar (Cerchio et al., 2015, see first row of their figure 3).

In summary, all features of colouration reported for B. omurai by Cerchio et al. (2015) were also evident in QE22.09.2007: (i) asymmetrical colouration of the lower jaws, with lightly pigmented right jaw (Figure 4) and darkly pigmented left jaw (Figure 5); (ii) asymmetrical colouration of the gape (inner lower lip) with whitish left gape (Figure 5) and darkly pigmented right gape; (iv) dark eye and ear stripes on the right side (Figure 4); (v) a third dark stripe (flipper-to-flank). A lightly pigmented chevron anterior to the dorsal fin and a blaze anterior to the right eye as reported by Cerchio et al. (2015) were not noticeable on photos of QE22.09.2007 and may, or may not, have been present. We must consider also the possibility of ontogenetic variation, as published descriptions are from subadults and adults, while QE22.09.2007 was evidently a calf. Whether the leading edge of the pectoral fins was white from tip to shoulder (Cerchio et al., 2015) neither could be ascertained, due to peeling skin in QE22.09.2007. 


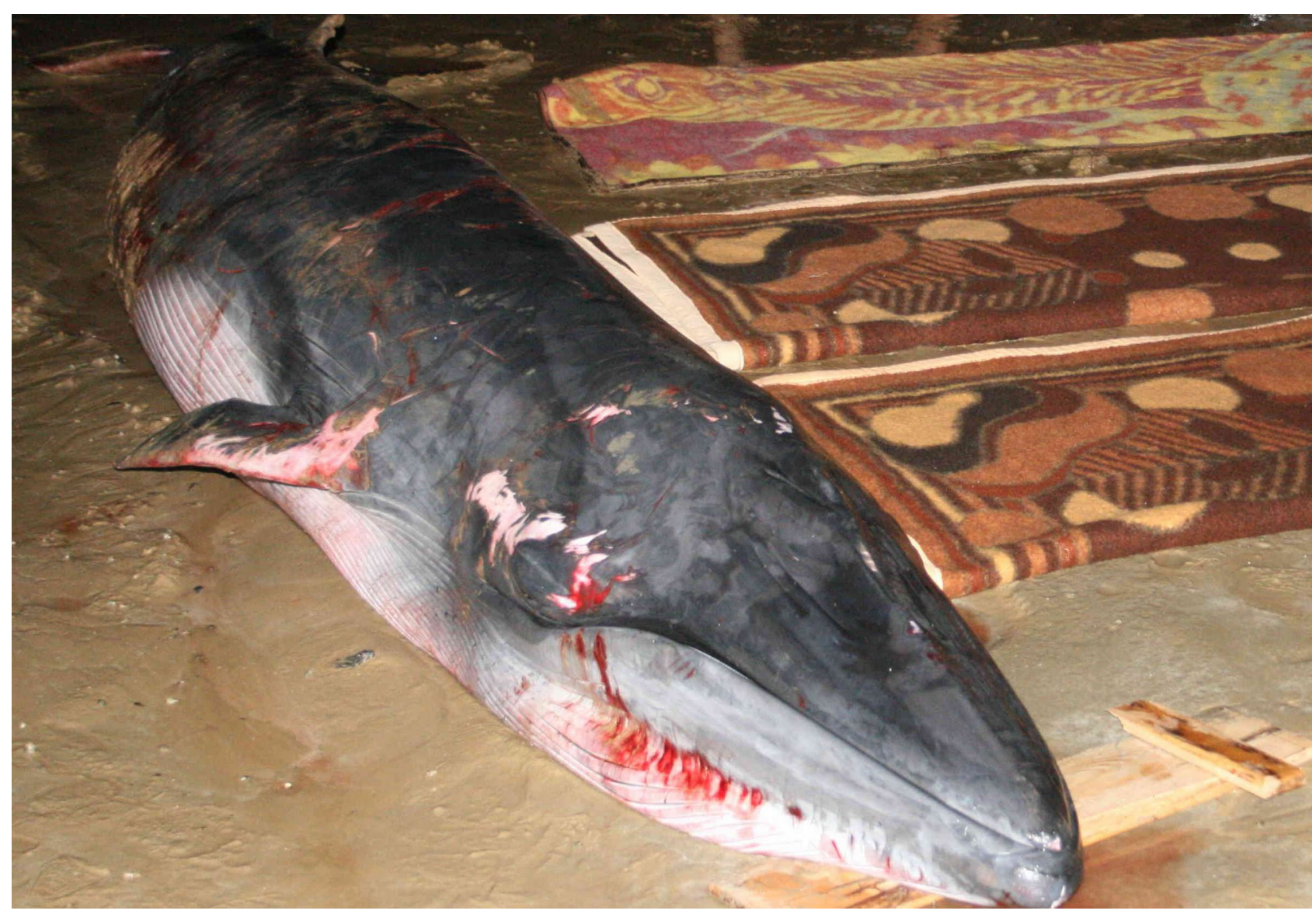

Figure 4. Right side of QE22.09.2007 while still alive, showing lightly pigmented, almost white throat, with light grey right mandible. Note three head stripes: (1) dark grey, wide eye stripe; (2) narrow ear stripe; and (3) wide flipper-toflank stripe. Visible are also the central rostral ridge and two faint partial accessory ridges.

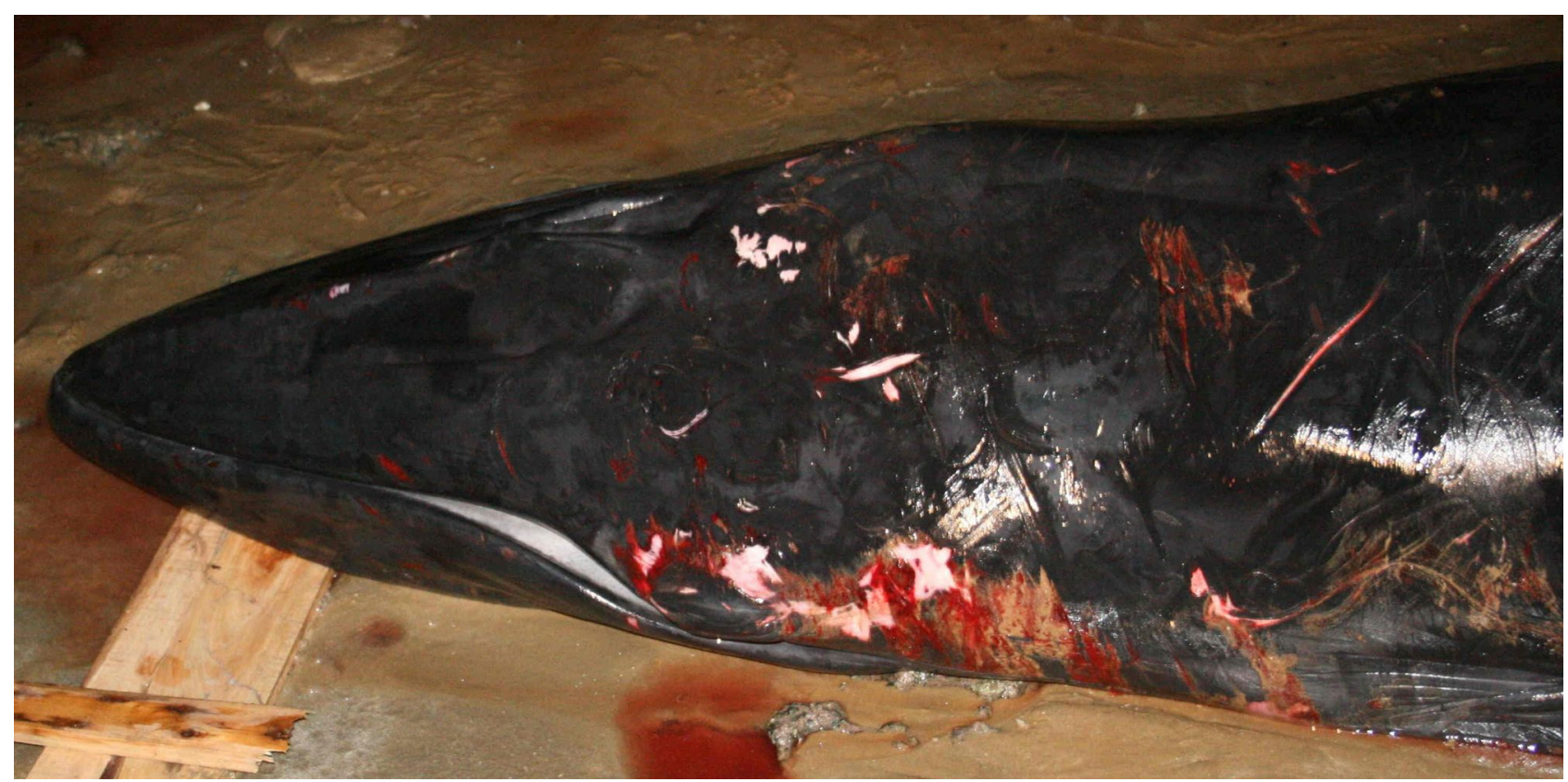

Figure 5. Overal dark pigmentation of the left body side of specimen QE22.09.2007, and in particular the uniformly darkly pigmented throat and left mandible contrasts with its paler right side (Figure 4). However note lighter pigmented left gape. 
bioRxiv preprint doi: https://doi.org/10.1101/042614; this version posted March 7, 2016. The copyright holder for this preprint (which was not certified by peer review) is the author/funder. All rights reserved. No reuse allowed without permission.

\section{Short Title: Omura's whale in the Persian Gulf}

\section{Faint indications of lateral rostral ridges}

In contrast with the prominent lateral ridges on the rostrum in Bryde's whales, commonly characterized as diagnostic, the lateral rostral ridges are faint in Omura's whales (Wade et al., 2003; see figure 3 in Cerchio et al., 2015). In QE22.09.2007 a faint left lateral ridge was formed between two parallel grooves present on the left side of the rostrum, while on the right side, relief of the rostral integument was visible only proximally due to two very short parallel grooves (Figure 6). Actually these sets of parallel grooves appeared to be responsible for the faint lateral ridge aspect, as there seemed to be no true raised ridges as in Bryde's whales. More $B$. omurai specimens will be necessary to better describe the extent of individual and ontogenetic variation in rostral grooves and ridges. However, it is evident that both minke whale species which have a single strongly raised central ridge on the rostrum, and laterally show no relief of the rostral integument, are not concordant with the morphology observed in QE22.09.2007.

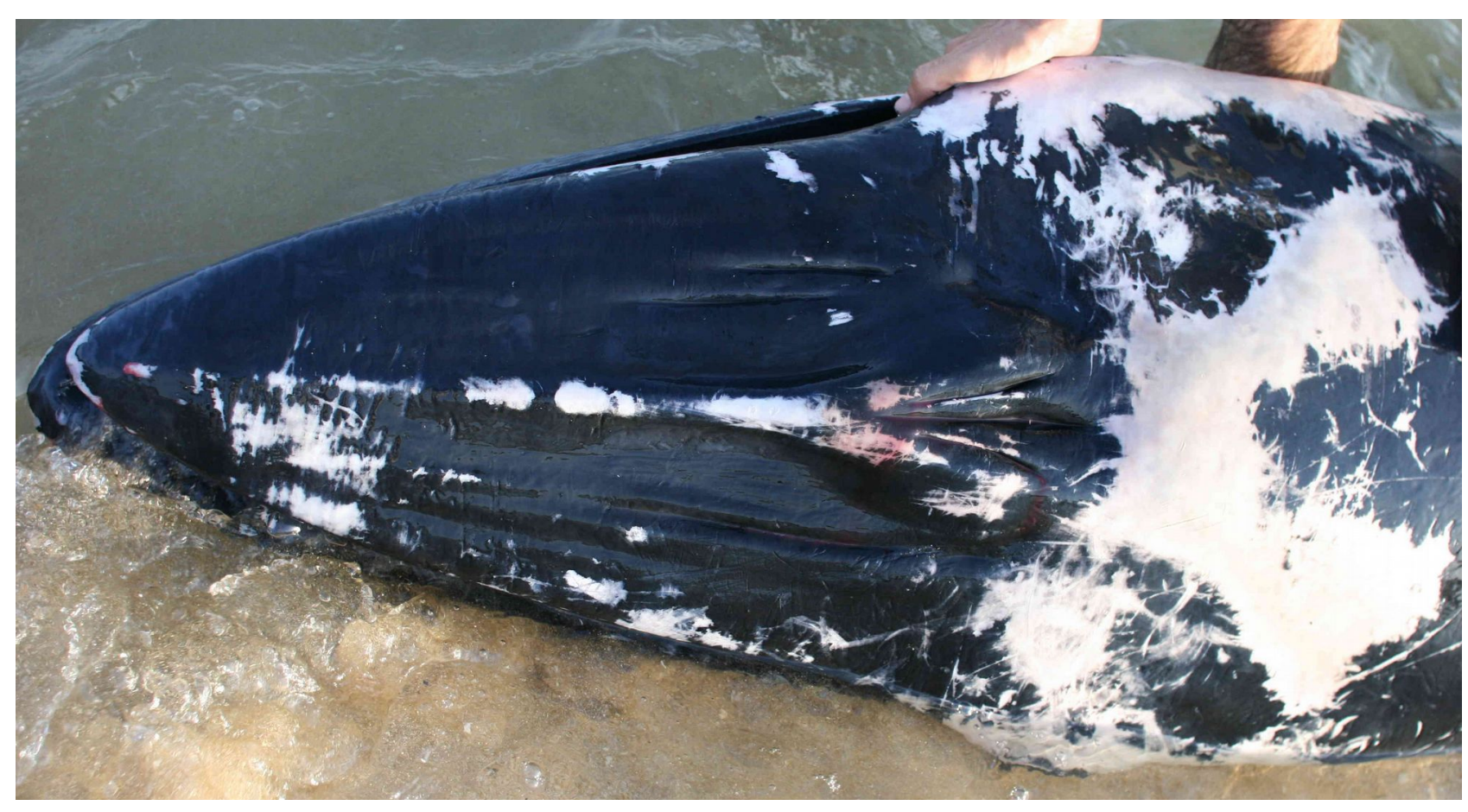

Figure 6. Dorsal view of head of QE22.09.2007 showing peculiar configuration of a relatively low central rostral ridge, a faint left lateral ridge and a system of two very short grooves, proximally, on the right side of the rostrum, providing a general aspect of incomplete and faint lateral ridges. The rostrum was largely flat and not slightly arched in crosssection as in minke whales.

Low number of baleen plates.

An approximate count of 204 baleen plates in the right jaw, determined from several close-up photographs of the head of QE22.09.2007 (Figure 7) agrees with baleen plate counts reported for B. omurai : 203 (right side) in one whale and 208 (left side) in another whale, while 181-190 (right side) in a third specimen (Wada et al., 2003). Baleen counts in B. omurai are markedly lower than those for the other Balaenoptera species (Wada et al., 2003). There exists no overlap even with the lower extreme of the range in Bryde's whales (276-289 plates per jaw) (Best, 2007) and Antarctic minke whales (215-310 plates per jaw) (Best, 2007). 


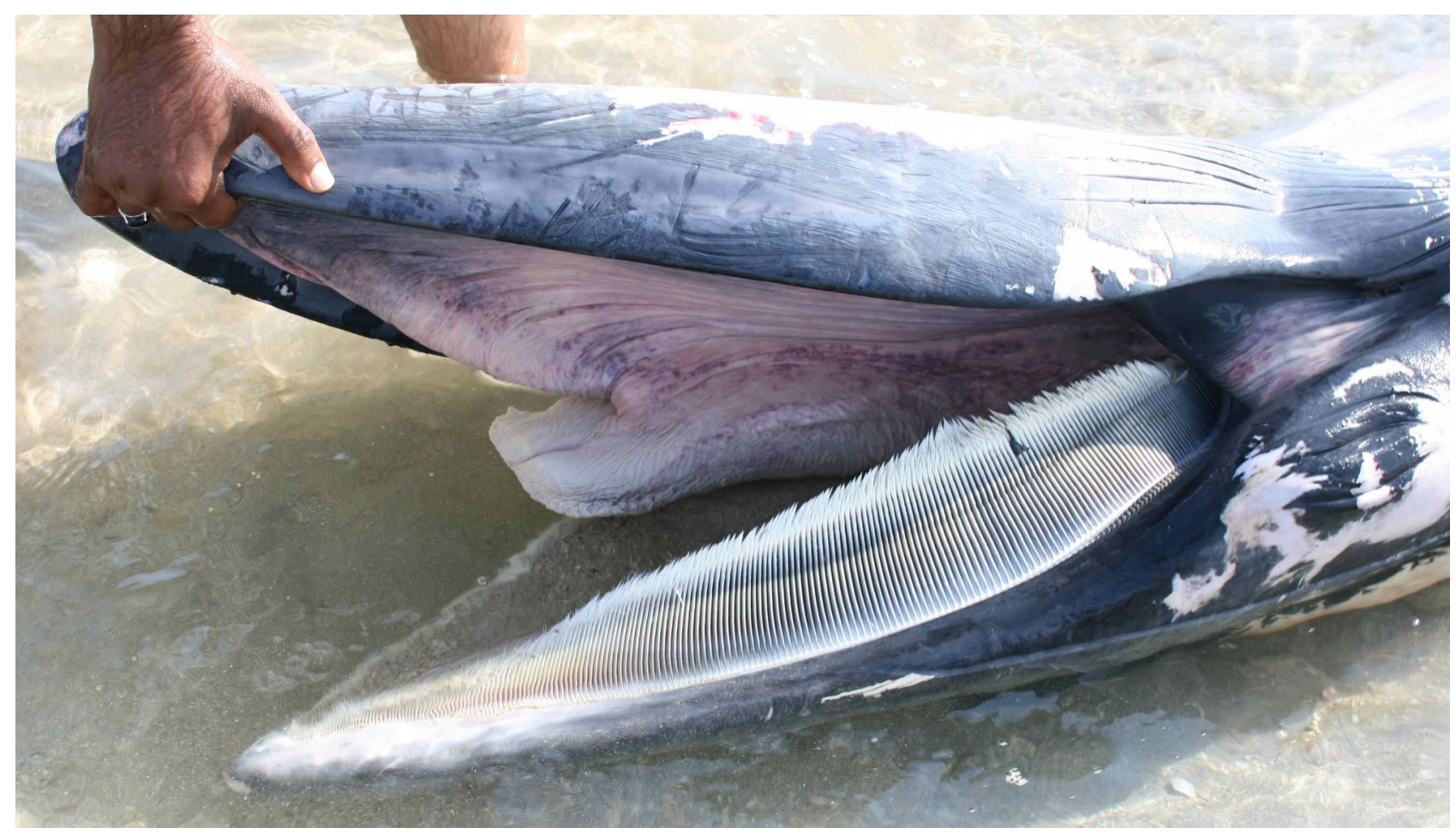

Figure 7. Right side view of the head (upside down) of specimen QE22.09.2007 showing the low number of short but broad baleen plates, with greyish-white baleen fringes, as reported for B. omurai (Wada et al., 2003). The colour of the baleen plates varied with their anteroposterior position in the baleen row and displayed asymmetry.

\section{Conclusion}

The combination of seven principal morphological features is considered diagnostic evidence for the positive identification of QE22.09.2007 as B. omurai. With no evidence of emaciation or any external trauma other than minor cuts and abrasions associated to the event of running ashore, the cause of stranding is unknown. However, the event was strongly reminiscent of the recent stranding of a similar-sized juvenile specimen of B. omurai in Mauritania (Jung et al., 2015). As the latter, QE22.09.2007 apparently was also either an unweaned calf or a recently weaned one. An adult female (mother) may have occurred in the vicinity. The likelihood for a local B. omurai population in the northern Arabian Sea seems higher than the wandering of a very young animal or mother/calf pair from any of the known distant distribution areas in the eastern Indian Ocean or in the SW Indian Ocean (Madagascar).

Generally, Omura's whale may be far more wide-spread than currently available records seem to suggest (reviewed in Cerchio et al., 2015). In the northeast Indian Ocean, there are specimens from the west coast of Thailand (Yamada et al., 2006; Adulyanukosol, 2012) and graphic evidence from the eastern Andaman Sea. The species occurs also on the west side of the Malay Peninsula, in Malaysia (Ponnanpalam, 2012) and off the Cocos Islands (Wada et al., 2003). However genetic sampling of Bryde's whale populations in the North Indian Ocean, including the Arabian Sea, Bay of Bengal, the Maldives and south of Java, have not yet revealed evidence of $B$. omurai. The suggestion by Cerchio et al. (2015) that the species distribution may be discontinuous and that the Madagascar population in the southwest Indian Ocean may be relatively isolated from the eastern populations is possible but as yet unconfirmed. These authors admitted however that it is conceivable that other populations have gone undetected, with accounts from the Cocos Islands and Madagascar suggesting that populations occur around oceanic islands. Boat surveys should be undertaken east and south of Qeshm Island in search of a potential Iranian population of Omura's whale.

It is adamant also that more stranded whales be systematically examined, photographed and sampled in the 


\section{Short Title: Omura's whale in the Persian Gulf}

Persian Gulf. We know for instance that from March to October 2015 at least four whales stranded on Iran's Persian Gulf coasts (S. Ranjbar, unpublished data), but none have been studied.

The successive findings of $B$. omurai in formerly unrecognised areas of distribution (Madagascar, Mauritania, Iran) hint that the more likely scenario is of a far wider tropical and subtropical, perhaps pantropical, distribution of $B$. omurai than hitherto documented. Earlier specimens may have been incorrectly identified as Bryde's whales considering that most diagnostic morphological features of $B$. omurai have been described only in the past few years (Wada et al., 2003; Cerchio et al., 2015; Jung et al., 2015).

\section{Acknowledgements}

The authors thank Mr Asghar Besharati for kindly providing a video copy for examination. Van Waerebeek warmly thanks the Qeshm Department of Environment, Qeshm Free Area, Qeshm City, Iran, for supporting two short study visits to Qeshm Island in 2014-2015.

\section{References}

Adulyanukosol K, Thongsukdee S, Passada S, Prempree T, Wannarangsee T. 2012. Bryde’s whales in Thailand. Bangkok, Thailand: Aksornthai Printing Co.

Best, P.B. (2007) Whales and Dolphins of the Southern African Subregion. Cambridge University Press. 338pp.

Braulik, G.T.S., Ranjbar, S., Owfl, F., Aminrad, T., Dakhteh, S.M.H., Kamrani, E. \& Mohsenizadeh, F. 2010. Marine mammal records from Iran. J. Cet. Res.Manag. 11: 49-63.

Jefferson, T.A., Webber, M.A. \& Pitman, R.L. (2008) Marine Mammals of the World. A comprehensive Guide to their identification. Academic Press, Amsterdam. 573pp.

Jung J.L., Mullié, W.C., Van Waerebeek, K., Wagne, M.M., Bilal, A.S.O., Sidaty, Z.A.O., Toomey, L., Méheust, E. \& Marret, F. (2015) Omura's whale off West Africa: autochthonous population or inter-oceanic vagrant in the Atlantic Ocean? Mar. Biol. Res. DOI:10.1080/17451000.2015.1084424

Kato, H. \& Fujise, Y. (2000) Dwarf minke whales: morphology, growth and life history with some analyses on morphometric variation among the different forms and regions. Paper SC/52/OS3, SC International Whaling Commission, Adelaide, Australia, June 2000, 30pp.

Olsen, O. 1913. On the external characters and biology of Bryde's whale (Balaenoptera brydei), a new rorqual from the coast of South Africa. Proceedings of the Zoological Society of London 1913: 1073-1090.

Ponnampalam LS. (2012) Opportunistic observation on the distribution of cetaceans in the Malaysian South China, Sulu and Sulawesi Seas and an updated checklist of marine. Raffles B Zool. 60, 221-231.

Reilly, S.B., Bannister, J.L., Best, P.B., Brown, M., Brownell Jr., R.L., Butterworth, D.S., Clapham, P.J., Cooke, J., Donovan, G.P., Urbán, J. \& Zerbini, A.N. 2008a. Balaenoptera omurai. The IUCN Red List of Threatened Species 2008: e.T136623A4319390. Downloaded on 03 November 2015.

Reilly, S.B., Bannister, J.L., Best, P.B., Brown, M., Brownell Jr., R.L., Butterworth, D.S., Clapham, P.J., Cooke, J., Donovan, G.P., Urbán, J. \& Zerbini, A.N. 2008b. Balaenoptera edeni. The IUCN Red List of Threatened Species 2008: e.T2476A9445502. Downloaded on 03 November 2015.

Sasaki, T., Nikaido, M., Wada, S., Yamada, T. K., Cao, Y., Hasegawa, M. and Okada, N. 2006. Balaenoptera omurai is a newly discovered baleen whale that represents an ancient evolutionary lineage. Molecular Phylogenetics and Evolution 41: 40-52.

Wada, S., Oishi, M. \& Yamada, T.K. (2003) A newly discovered species of living baleen whale. Nature 426, 278-281. [doi:10.1038/nature02103].

Yamada TK et al. 2006 Middle-sized balaenopterid whale specimens (Cetacea: Balaenopteridae) preserved at several institutions in Taiwan, Thailand, and India. Mem. Natl Sci. Mus. Tokyo 44, 1-10. 